\title{
Behavioral contrast in pigeons and rats: A comparative analysis
}

\author{
JAMES D. DOUGAN and VALERI A. FARMER-DOUGAN \\ Indiana University, Bloomington, Indiana \\ and \\ FRANCES K. MCSWEENEY \\ Washington State University, Pullman, Washington
}

\begin{abstract}
The effects of reinforcement rate on behavioral contrast were examined in pigeons and rats. Each species was exposed to a series of 12 multiple variable-interval schedules, divided into four 3-schedule series. Each series consisted of a standard contrast manipulation, and baseline schedules provided a different rate of reinforcement in each of the series. The functions relating reinforcement rate to the magnitude of contrast were different across species. Rats showed a U-shaped function, with reliable contrast occurring only at high reinforcement rates. Pigeons showed an inverted U-shaped function, with contrast occurring on all schedules except the schedule providing the lowest rate of reinforcement. Pigeons discriminated between schedule components better than rats did, although differences in discrimination were probably not responsible for the differences in contrast. The results suggest that behavioral contrast in rats may be a different phenomenon from behavioral contrast in pigeons. The results cannot be explained by current theories, which view contrast as the product of a single general process.
\end{abstract}

The rate of a reinforced response is a joint function of the rate of reinforcement for that response and the rate of other reinforcers available in the context. One example is multiple schedule behavioral contrast (Reynolds, 1961). A multiple schedule consists of two or more alternating schedules of reinforcement (or components), each associated with a discriminative stimulus. Behavioral contrast on multiple schedules is an inverse relationship between the rate of response during one component of a multiple schedule and the rate of reinforcement provided in the other component (McSweeney \& Norman, 1979).

Positive behavioral contrast is an increase in the rate of responding in one component of the multiple schedule resulting from a decrease in the rate of reinforcement in the other component. Positive contrast is commonly studied using a three-schedule series (McSweeney \& Norman, 1979). During the first, or initial baseline, phase, the multiple schedule components provide the same rate of reinforcement. During the second, or contrast, phase, one of the components (changed component) is changed to extinction. The reinforcement rate in the other component (constant component) remains the same. The third, or baseline recovery, phase is identical to the initial base-

This research was conducted at Washington State University. Preparation of this manuscript was supported by a National Institute of Mental Health postdoctoral fellowship to James D. Dougan at Indiana University. Portions of the data were presented at the meeting of the Association for Behavior Analysis, May 1986. We wish to thank Eliot Hearst for his helpful comments on an earlier version of this manuscript. Requests for reprints should be addressed to James D. Dougan, Department of Psychology, Indiana University, Bloomington, IN 47405. line phase. Positive contrast occurs if the response rate in the constant component during the contrast phase is higher than the response rate in the same component during the baseline phases

Behavioral contrast has received considerable attention in the literature (see Williams, 1983, for review). With a few notable exceptions (e.g., Bitterman, 1975; Pert \& Gonzalez, 1974), extensive study of behavioral contrast has been limited to pigeons pecking keys and (to a lesser extent) rats pressing bars. There are indications of species differences between even this limited set of species. For example, behavioral contrast is a very robust phenomenon in pigeons, and it occurs over a wide variety of schedule manipulations (e.g., Schwartz \& Gamzu, 1977; Williams, 1983). Although contrast effects clearly do occur in rats (Beninger \& Kendall, 1975; Blough, 1980; Bradshaw, Szabadi, \& Bevan, 1978; Dougan, McSweeney, \& Farmer, 1985, 1986; Gutman, 1977; Gutman, Sutterer, \& Brush, 1975; Nallan \& McCoy, 1979; Uhl \& Homer, 1974; Wilkie, 1972), they are less robust than similar effects in pigeons. Some authors (e.g., Rachlin, 1973; Schwartz \& Gamzu, 1977) have even argued that contrast does not occur in rats.

Despite suggestions that contrast in pigeons is different from contrast in rats, these differences have been impossible to interpret. Comparisons across studies are difficult because earlier studies have used different schedules and procedures, with little direct overlap among studies. In addition, little effort has been made to isolate the factors that contribute to species differences. Thus, despite apparent species differences, little is known about the variables of which these differences are a function. 
McSweeney (1978) suggested that Bitterman's (1960, 1965) functional relations approach is appropriate for the study of behavioral contrast across species and response systems. In the functional relations approach, species are compared across several levels of an independent variable to determine whether responding in the species changes in the same way as a function of the same variables. The functional relations approach, therefore, may be used to determine the dimensions along which species differ.

Recently, Dougan et al. $(1985,1986)$ suggested that reinforcement rate may be an important dimension of species differences in behavioral contrast. They found reliable positive contrast in rats only when baseline schedules provided high rates of reinforcement (greater than 240 reinforcers per hour). Pigeons, on the other hand, show contrast on a wide variety of schedules, and may in fact show more contrast when baseline schedules provide a relatively low rate of reinforcement (Reynolds, 1963; Spealman \& Gollub, 1974; but see McSweeney, Dougan, Higa, \& Farmer, 1986). Again, these apparent species differences cannot be interpreted because the studies used different procedures and schedules. A direct comparison of the effects of reinforcement rate on contrast in pigeons and rats needs to be conducted so that the dimensions of species differences may be isolated.

An examination of the effects of reinforcement rate on behavioral contrast across species is also theoretically important. At least three major theories have been proposed to account for behavioral contrast: matching theory (Hermstein, 1970; Williams, 1983), competition theory (Ettinger \& Staddon, 1982; Hinson \& Staddon, 1978; Staddon, 1982), and additivity theory (Gamzu \& Schwartz, 1973; Hearst \& Jenkins, 1974; Rachlin, 1973). These theories differ on at least two dimensions that are relevant to the present study. First, both matching theory and competition theory fail to predict species differences in behavioral contrast, whereas additivity theory does predict species differences. Second, both matching theory and competition theory make direct predictions about the effects of reinforcement rate on the magnitude of behavioral contrast. The following brief review demonstrates these differences.

According to matching theory, behavioral contrast is a by-product of matching (Baum, 1974; Herrnstein, 1970). According to the matching law, the ratio of responses made on two concurrently available schedules of reinforcement will equal the ratio of reinforcement rates provided by those schedules. Herrnstein (1970) extended the matching law to multiple schedules, in which the two sources of reinforcement are not concurrently available. According to Herrnstein's analysis, the magnitude of behavioral contrast on a standard three-schedule series is described by Equation 1 (derived from Herrnstein, 1970; see Staddon, 1982, for a similar derivation):

$$
C o=\frac{r_{1}+m r_{2}+r_{0}}{r_{1}+r_{0}},
$$

where $\mathrm{Co}$ is a ratio representing the magnitude of behavioral contrast. Specifically, Co refers to the rate of responding in the constant component during the contrast phase divided by the rate of responding in the constant component during the baseline phases. The rates of reinforcement provided by the constant and changed components are represented by $r_{1}$ and $r_{2}$, respectively. Two free parameters, $m$ and $r_{0}$, represent the degree of interaction between components and the rate of reinforcement from unscheduled sources, respectively.

Equation 1 predicts that the magnitude of behavioral contrast $(\mathrm{Co})$ will increase with increases in baseline reinforcement rate $\left(r_{1}\right.$ and $\left.r_{2}\right)$. Equation 1 also leaves little room for species differences. Species differences might occur if different species had different values for the $m$ and $r_{0}$ parameters; however, the ways in which these parameters might differ across species have not been specified.

According to competition theory, behavioral contrast occurs because of reduced competition in the unchanged component between the instrumental response and the alternative responses. When the rate of reinforcement in the changed component is changed to extinction, alternative responses are re-allocated from the unchanged component to the changed component. This allows instrumental responding in the unchanged component to increase because of reduced competition with alternative responding. The magnitude of contrast will thus be determined by the amount of re-allocation that is possible on a given multiple schedule. The amount of re-allocation possible, in turn, is a function of the amount of reinforcement for the instrumental response relative to the amount of reinforcement for alternative responses. This function is described by Equations 2 and 3 (from Staddon, 1982):

$$
C o=\frac{r_{1}+.5 r_{0}}{r_{1}}, \quad r_{0}<r_{1}
$$

and

$$
C o=\frac{2 r_{1}+r_{0}}{r_{1}+r_{0}}, \quad r_{0}>r_{1} .
$$

As in Equation 1, Co is a ratio representing the magnitude of behavioral contrast, $r_{1}$ is the rate of reinforcement in the constant component, and $r_{0}$ is a parameter representing reinforcement for alternative responses. Equations 2 and 3 predict that the magnitude of contrast will first increase (Equation 3) and then decrease (Equation 2) with increases in the rate of reinforcement during baseline $\left(r_{1}\right)$. Like Equation 1, Equations 2 and 3 leave little room for species differences. Species differences might be expressed in the $r_{0}$ parameter, but exactly how the parameter might change has not been specified.

According to additivity theory, behavioral contrast results from the summation of operant and Pavlovian responding. Operant responding should occur whenever reinforcement is contingent on a response, whereas Pavlovian responding should occur when a stimulus differentially predicts reinforcement. During the baseline phase 
of a contrast series, only operant responding should occur because the two components provide the same rate of reinforcement. During the contrast phase, however, Pavlovian responding should also occur because the stimulus that signals a change in components differentially predicts reinforcement.

Additivity theory does not make any direct predictions about the effects of reinforcement rate on behavioral contrast. The strong version of the additivity theory (see McSweeney, Ettinger, \& Norman, 1981) does predict species differences. According to the strong version of additivity, contrast will occur when operant and Pavlovian responses have similar topographies. For example, contrast might occur when pigeons peck keys for food because pigeons also peck keys as a result of Pavlovian training (i.e., autoshaping; Brown \& Jenkins, 1968). Because rats are less likely to press bars during Pavlovian training (Boakes, 1977), they also would be less likely to show contrast.

The present study, therefore, compared behavioral contrast in pigeons with behavioral contrast in rats across different baseline rates of reinforcement. Baseline reinforcement rate was chosen as an independent variable because previous studies have suggested that it may be an important dimension of species differences. In addition, the three major theories of behavioral contrast make different predictions about the effects of baseline reinforcement rate on behavioral contrast.

\section{METHOD}

\section{Subjects}

The subjects were 5 naive Sprague-Dawley rats (R128, R129, $R 130, R 131$, and $R 132$ ) and 4 naive homing pigeons (P29, P30, $\mathrm{P} 31$, and $\mathrm{P} 32$ ) obtained from the Washington State University Psychology Department vivarium. A 5th pigeon (P28) died during the course of the experiment. The subjects were housed individually and were maintained at approximately $80 \%$ of their ad-lib weights throughout the experiment.

\section{Apparatus}

The apparatus for rats was a standard operant conditioning unit, $21 \mathrm{~cm}$ in width, $23 \mathrm{~cm}$ in length, and $19 \mathrm{~cm}$ in height. A single response bar was located on the front wall, $9 \mathrm{~cm}$ from the wiregrid floor and $1.5 \mathrm{~cm}$ from the left wall. The bar was $5 \mathrm{~cm}$ wide, and required a force of $.35 \mathrm{~N}$ to operate. Two 5-W white cue lights were mounted $5 \mathrm{~cm}$ above the bar, $4 \mathrm{~cm}$ from each other. Food was delivered through a $5 \times 5 \mathrm{~cm}$ recessed food cup, which was positioned at floor level in the front wall, $8 \mathrm{~cm}$ from the side walls. Two 5-W houselights were mounted in the ceiling of the chamber, directly adjacent to the rear wall and $8 \mathrm{~cm}$ from the two side walls. The entire apparatus was housed in a sound-attenuating chamber. An exhaust fan masked noise from the nearby electromechanical programming equipment.

The apparatus for pigeons was a standard three-key Grason-Stadler chamber, measuring $34 \times 29 \times 28 \mathrm{~cm}$. Three Plexiglas response keys, each $2 \mathrm{~cm}$ in diameter, were spaced evenly across the front wall. Only the center key, which was located $23 \mathrm{~cm}$ from the floor of the chamber, was used during the experiment. A force of approximately $.05 \mathrm{~N}$ was required to operate the key. The key was illuminated from behind by a single $5-\mathrm{W}$ bulb. The color of the light projected on the key could be varied by projection filters. A food hopper, approximately $5 \times 5 \mathrm{~cm}$, was located directly below the center response key, approximately $7.5 \mathrm{~cm}$ from the floor of the chamber. The hopper was illuminated from within by a single 5-W light. A 5-W houselight was located in the upper right-hand corner of the chamber. The entire chamber was enclosed in a soundattenuating box, equipped with an exhaust fan that provided masking noise. Computerized control equipment was located in an adjacent room.

\section{Procedure}

The subjects were deprived to $80 \%$ of their ad-lib weights. Rats were hand shaped to press the response bar for food, and pigeons were autoshaped to peck the key for food. When all subjects were reliably performing the correct response, they were exposed to 12 multiple variable-interval variable-interval (mult VI VI) and multiple variable-interval extinction (mult VI EXT) schedules, as outlined in Table 1.

The 12 schedules may be divided into four 3 -schedule series, with each series representing a standard 3-schedule behavioral contrast manipulation (McSweeney \& Norman, 1979). Each series consisted of an initial baseline schedule in which both components of the multiple schedule provided the same rate of reinforcement, a contrast schedule in which one of the components was changed to extinction, and a baseline recovery condition identical to the first schedule. Baseline schedules provided a different rate of reinforcement in each series.

Multiple schedule components alternated once every $90 \mathrm{sec}$. For rats, the two lights immediately above the bar were illuminated during one component and were not illuminated during the other component. When the two components provided different rates of reinforcement (mult VI EXT), the lights were on during the VI component. For pigeons, components were signaled by the color of the center response key (red or white). When components provided different reinforcement rates, the keylight was red during the VI component and white during the EXT component.

Scheduled VI intervals were computed according to the arithmetic series suggested by Catania and Reynolds (1968, Appendix 2). Sessions were conducted daily, and were terminated when a fixed number of reinforcers had been delivered. This number changed across phases in order to keep session time roughly equal to $30 \mathrm{~min}$. The number of reinforcers per session was adjusted downward during mult VI 15-sec VI 15-sec and mult VI 15-sec EXT schedules (second schedule series overall) to avoid possible satiation effects. Thus,

Table 1

Order of Presentation of Multiple Schedules Used in the Experiment, Number of Reinforcers Available per Session on Fach Schedule, and Number of Sessions Required for Stability on Each Schedule for Each Species

\begin{tabular}{llccc}
\hline $\begin{array}{c}\text { Constant } \\
\text { Component }\end{array}$ & $\begin{array}{c}\text { Changed } \\
\text { Component }\end{array}$ & $\begin{array}{c}\text { Reinforcers } \\
\text { per Session }\end{array}$ & $\begin{array}{c}\text { Sessions } \\
\text { to Stability } \\
\text { (Rats) }\end{array}$ & $\begin{array}{c}\text { Sessions } \\
\text { to Stability } \\
\text { (Pigeons) }\end{array}$ \\
\hline VI 60-sec & VI 60-sec & 30 & 23 & 22 \\
VI 60-sec & EXT & 15 & 32 & 29 \\
VI 60-sec & VI 60-sec & 30 & 21 & 28 \\
VI 15-sec & VI 15-sec & 80 & 30 & 45 \\
VI 15-sec & EXT & 40 & 43 & 40 \\
VI 15-sec & VI 15-sec & 80 & 22 & 46 \\
VI 30-sec & VI 30-sec & 60 & 29 & 27 \\
VI 30-sec & EXT & 30 & 21 & 38 \\
VI 30-sec & VI 30-sec & 60 & 15 & 40 \\
VI 120-sec & VI 120-sec & 15 & 17 & 46 \\
VI 120-sec & EXT & 8 & 11 & 40 \\
VI 120-sec & VI 120-sec & 15 & 11 & 45 \\
\hline
\end{tabular}


the sessions on those schedules were shorter than $30 \mathrm{~min}$. The number of reinforcers available during each session is listed in Table 1 . For rats, the reinforcer was a single $45-\mathrm{mg}$ Noyes pellet. For pigeons, the reinforcer was 4 -sec access to mixed grain.

Each schedule remained in effect until responding by all subjects in a species simultaneously met a stability criterion. Responding for a subject was considered stable when that subject's response rate within each component over the previous five sessions on a schedule was within the range of response rates for all previous sessions on that schedule. Stability criteria were evaluated separately for pigeons and rats, so the two species required a slightly different number of sessions to reach stability on each of the schedules. The number of sessions required to reach stability is presented in Table 1 for each species.

\section{RESULTS}

Response rates were calculated by dividing the number of barpresses or keypecks made in each component by the number of minutes spent in that component. The mean response rate in the unchanged component over the last 5 days of the baseline and contrast phases on each of the four series are presented in Table 2 for all subjects in the experiment. Data from the initial baseline and baseline recovery schedules were averaged to yield a single mean baseline score for each series. Behavioral contrast (denoted by an asterisk) was considered to occur when the rate of responding in the unchanged component during the contrast phase was higher than the rate of responding in the unchanged component during both the initial baseline and baseline recovery schedules.

As seen in Table 2, behavioral contrast occurred on at least one schedule series for each animal in the study. In general, pigeons showed contrast more often than rats, with most of the difference occurring on those schedule series that provided a moderate rate of reinforcement. All pigeons and all rats showed contrast during the mult VI 15 -sec series, and only 2 pigeons and 1 rat showed con-

Table 2

Mean Rate of Response in the Unhanged Component During Baseline (B) and Contrast (C) Schedules at Each Rate of Reinforcement, for Each Subject

\begin{tabular}{|c|c|c|c|c|c|c|c|c|}
\hline \multirow[b]{3}{*}{ Subject } & \multicolumn{8}{|c|}{ Scheduled Interreinforcer Interval } \\
\hline & \multicolumn{2}{|c|}{ VI 15-sec } & \multicolumn{2}{|c|}{ VI $30-\sec$} & \multicolumn{2}{|c|}{ VI 60-sec } & \multicolumn{2}{|c|}{ VI $120-\mathrm{sec}$} \\
\hline & B & $\mathrm{C}$ & B & $\mathrm{C}$ & $\mathbf{B}$ & $\mathrm{C}$ & B & C \\
\hline \multicolumn{9}{|c|}{ Rats } \\
\hline R128 & 90.4 & $122.1^{*}$ & 90.5 & 53.3 & 27.2 & 12.3 & 14.7 & 13.4 \\
\hline R129 & 26.6 & $34.2^{*}$ & 44.0 & 27.2 & 27.0 & 16.1 & 7.7 & $10.3 *$ \\
\hline $\mathbf{R} 130$ & 44.2 & $52.2 *$ & 69.7 & 45.4 & 12.2 & 7.3 & 13.7 & 11.3 \\
\hline R 131 & 63.2 & $66.8 *$ & 49.8 & $72.0^{*}$ & 23.4 & 8.0 & 23.6 & 14.1 \\
\hline R 132 & 72.2 & $79.6^{*}$ & 34.3 & 41.1 & 16.6 & 4.5 & 13.2 & 17.4 \\
\hline \multicolumn{9}{|c|}{ Pigeons } \\
\hline P29 & 97.6 & $141.7^{*}$ & 70.8 & $98.0^{*}$ & 93.0 & $165.3^{*}$ & 79.3 & $82.0^{*}$ \\
\hline P30 & 108.4 & $132.8^{*}$ & 87.0 & $114.0^{*}$ & 77.4 & $140.4^{*}$ & 64.1 & 60.1 \\
\hline P31 & 87.1 & 133.3* & 74.5 & $106.6^{*}$ & 75.6 & $112.2^{*}$ & 67.2 & $80.8^{*}$ \\
\hline P32 & 98.6 & $137.9 *$ & 78.4 & 81.3 & 79.9 & $181.9^{*}$ & 36.6 & 27.1 \\
\hline
\end{tabular}

Note-Scores for the baseline condition represent the mean of the initial baseline and baseline recovery schedules. *Instances of behavioral contrast.

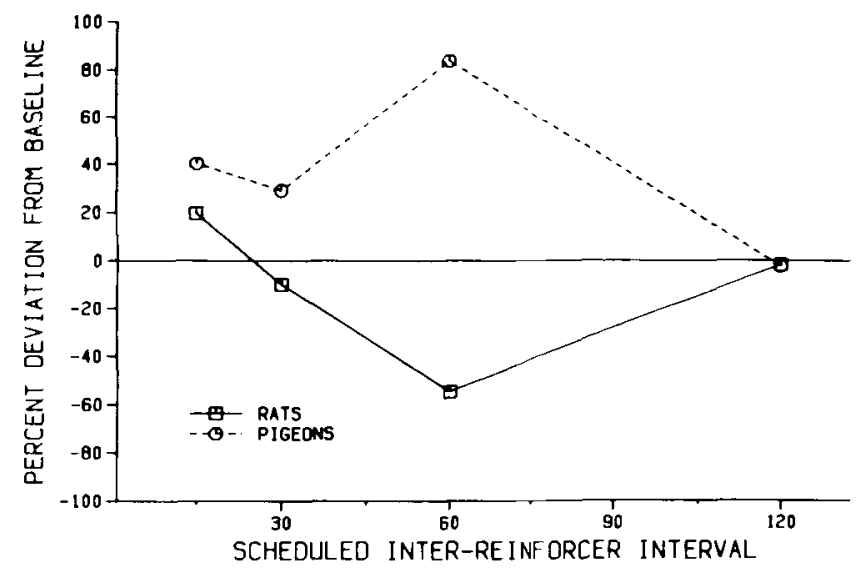

Figure 1. Mean percent deviation from baseline plotted as a function of scheduled baseline interreinforcer interval for both pigeons and rats. A positive value represents positive behavioral contrast.

trast on the mult VI 120-sec series. On the mult VI $30-$ sec schedule, 3 of 4 pigeons showed contrast, but only 1 rat showed contrast. Likewise, all of the pigeons showed contrast during the mult VI 60-sec series, but none of the rats showed contrast on that series.

The rate measures in Table 2 were transformed into deviation from baseline scores by dividing the rate of responding in the constant component during the contrast schedule by the average rate of responding in that component during the two surrounding baseline schedules, multiplying by 100 , and subtracting 100 from the result. This yields a percentage of deviation from baseline score, in which a positive value represents positive behavioral contrast, a zero value represents no change in response rate relative to baseline, and a negative score represents negative induction.

Figure 1 plots the mean percentage of deviation from baseline over the last 5 days of each schedule series as a function of the scheduled baseline interreinforcer interval for both rats and pigeons. Visual inspection of Figure 1 suggests that the function relating percentage of deviation from baseline to the reinforcement rate provided during baseline was quite different in rats and pigeons. A two-factor (species $X$ schedule) mixed-design analysis of variance confirmed this visual analysis. There was a significant effect of species $[F(1,7)=134.21, p<.001]$ and a significant species $\times$ schedule interation $[F(3,21)$ $=10.87, p<.001]$. There was no significant effect of schedule.

Two additional tests were used to analyze the deviation from baseline data presented in Figure 1. First, the reliability of behavioral contrast was assessed with a onetailed $t$ test for comparison between a sample mean (the mean percentage of deviation for each species on each schedule series) and a population mean (the null hypothesis of zero or negative deviation). Thus, a significant $t$ score would represent a reliable positive deviation from baseline, or positive behavioral contrast. For rats, the addi- 
tional comparisons showed significant positive behavioral contrast only on the schedule providing the highest rate of reinforcement $[t(4)=3.62, p<.05]$. Pigeons showed significant positive contrast when the baseline schedule was mult VI $15-\sec$ VI $15-\sec [t(3)=6.30, p<.005]$, mult VI 30-sec VI 30-sec [t(3) $=3.29, p<.025]$, and mult VI 60-sec VI 60-sec [t(3) $=5.12, p<.01]$.

An analysis of orthogonal polynomials assessed whether the function relating percentage of deviation to baseline reinforcement rate was different for the two species. Linear and quadratic weightings were obtained from the logarithm of scheduled interreinforcement interval because this allowed the use of equal-interval weightings. There was a significant interaction between species and the quadratic comparison $[F(1,7)=19.81, p<.01]$, indicating that the functions were indeed different for the two species, and that the difference lies in the quadratic component.

The results suggest that pigeons and rats show different functions relating the magnitude of contrast to the rate of reinforcement provided by baseline schedules. It is possible that the different functions are related to discrimination. For example, if discrimination were better in one of the species, then that species might be more sensitive to changes in reinforcement rate, and thus show more behavioral contrast (Rachlin, 1973; Williams, 1983). Coefficients of discrimination were calculated in order to assess this possibility. The coefficients were calculated for each subject on each schedule series by dividing the rate of responding in the VI component during contrast schedules by the sum of the rates of responding in both VI and EXT components during contrast schedules. The degree to which this score exceeds 0.5 indicates the degree of discrimination between the two multiple schedule components during mult VI EXT. The mean discrimination ratio in each species on each schedule is plotted as a function of scheduled baseline reinforcement rate in Figure 2.

As seen in Figure 2, the discrimination coefficient was higher for pigeons than for rats on all schedules. A twofactor (species $\times$ schedule) mixed-design analysis of variance confirmed this, yielding a significant effect for spe-

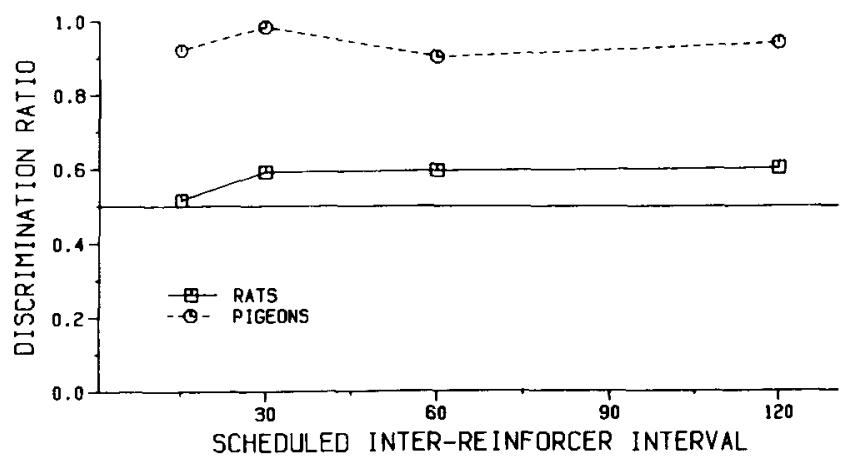

Figure 2. Mean discrimination coefficients plotted as a function of scheduled baseline interreinforcer interval for both pigeons and rats. $A$ value above 0.5 represents discrimination. cies $[F(1,7)=347.12, p<.001]$. There was also a significant effect of schedule $[F(3,21)=5.70, p<.01]$ and a significant species $\times$ schedule interaction $[F(3,21)=$ $3.10, p<.05]$. A $t$ test for differences between a sample mean (the mean discrimination coefficient for each species on each schedule) and a population mean (the 0.5 null hypothesis) was used to assess the presence or absence of discrimination on each schedule. Discrimination ratios were significantly $(p<.05)$ greater than 0.5 for both species on all schedule series except for rats on the mult VI 15-sec VI 15-sec series $[t(4)=1.37, p>.10]$.

\section{DISCUSSION}

The present experiment used a standard contrast manipulation to examine the effects of baseline reinforcement rate on the magnitude of positive behavioral contrast in rats and pigeons. Several species differences were found. First, the function relating contrast to reinforcement rate in rats was $U$-shaped, whereas the function for pigeons was an inverted U. Second, rats showed reliable positive behavioral contrast only at high reinforcement rates, whereas pigeons showed contrast on all schedules except that providing the lowest rate of reinforcement. Third, rats showed relatively poor discrimination, whereas pigeons showed relatively good discrimination. Finally, rats failed to show significant discrimination on the one schedule series in which they also showed positive behavioral contrast. ${ }^{1}$ Pigeons showed significant discrimination on all schedules.

The present data support earlier suggestions based on comparisons between studies (Dougan et al., 1985, 1986; Reynolds, 1963; Spealman \& Gollub, 1974) that behavioral contrast in rats changes differently from behavioral contrast in pigeons when the same variables are manipulated in a standard contrast paradigm. The present data also extend earlier reports (Dougan et al., 1985, 1986) that found behavioral contrast in rats only when baseline schedules provide a high rate of reinforcement. The finding of reliable contrast only at high reinforcement rates suggests why some authors (e.g., Rachlin, 1973; Schwartz \& Gamzu, 1977) have argued that contrast does not occur in rats. Most studies of contrast in rats do not provide such high reinforcement rates.

The implications of the present results rest heavily on the question of whether the "contrast" observed in rats is the same phenomenon as the "contrast" observed in pigeons. Although it is clear that the two species showed different functions relating contrast to the baseline reinforcement rate, it is unclear whether the contrast was really the same phenomenon in the two species. If contrast were the same phenomenon in the two species, then the observed species differences must have occurred because some uncontrolled variable(s) changed across the test conditions for the two species. Alternatively, the observed species differences may have occurred because contrast is actually a completely different phenomenon in rats and pigeons. 
Although every attempt was made to control variables across testing conditions for the two species, there are several possible uncontrolled variables. Perhaps the most likely of these is discrimination. Figure 2 shows that discrimination was relatively poor in rats, whereas discrimination was relatively good in pigeons. Because good discrimination is commonly assumed to be necessary for contrast to occur (Terrace, 1968; Williams, 1983), the differences in discrimination might explain why contrast was more reliable in pigeons than in rats.

Comparison with previous studies suggests that the discrimination "confound" was not responsible for the different functions relating contrast to reinforcement rate in the two species. For example, Dougan et al. (1985, Experiment 1) examined contrast in rats as a function of reinforcement rate under conditions roughly comparable to those in the present study. However, multiple schedule components in that study were arranged on different response bars, resulting in considerably better discrimination. Although the magnitude of contrast was somewhat higher than in the present study, they reported a decrease in the magnitude of contrast between VI 10-sec and VI 60-sec baseline schedules (see also Dougan et al., 1985, Experiment 2; Dougan et al., 1986). The reported decrease in the 1985 study virtually parallels the decrease over the same schedule range reported in the present study. Thus, changes in the magnitude of contrast appear to be independent of discrimination across this critical range of reinforcement rates.

Although discrimination does not explain the observed species differences, the present results do suggest that the relationship between contrast and discrimination needs further investigation. In particular, future research should investigate the counterintuitive finding of contrast in the absence of discrimination. This finding may be related to contrast on mixed schedules (Allison, 1976; Henke, 1972; Pear \& Wilkie, 1970) in which explicit discriminative stimuli are not present. Likewise, it is possible that the performance measures used in the present study masked a learned discrimination (Hearst, 1987).

Another potential confound is the maximum possible response rate. Because the present data were presented in terms of percentage of deviation, the absolute change in response rate required to maintain a constant percent deviation score increases as a function of increasing response rate during baseline. It is possible that the decrease in magnitude of contrast at high rates of reinforcement in pigeons may have occurred because of a ceiling effect: The birds might have been unable physically to produce response rates high enough to produce a proportionately large deviation from baseline. Examination of Table 2, however, suggests that this was not the case. For example, 3 of 4 birds showed higher rates of response during the VI 60 -sec series than during the VI 15 -sec series. Thus, a ceiling response rate cannot account for the lower magnitude of contrast on the VI 15-sec series.

Satiation is a third potential confounding factor. Rats showed contrast only at high rates of reinforcement. If satiation occurred near the end of the session during baseline mult VI 15-sec VI 15-sec schedules, a contrast effect might occur when conditions were changed to mult VI 15-sec EXT (in which fewer reinforcers were presented in the session) simply because satiation did not occur during the contrast phase. However, the number of reinforcers available per session on the mult VI 15-sec VI 15$\mathrm{sec}$ schedules was adjusted to avoid satiation effects. The adjustment was made on the basis of pilot data, which suggested that satiation would not be a factor. Informal observation also suggested that responding was steady across the session.

The testing conditions for the two species may have differed in many other ways. For example, it is not clear that a 45-mg Noyes pellet is equivalent to 4 sec of access to mixed grain as a reinforcer, that $80 \%$ deprivation levels are equivalent in pigeons and rats, or that pigeon keys and rat levers are equivalent as response manipulanda. Further research needs to examine the effects of these and other variables as possible dimensions of species differences. Although the failure to "control" these variables might be a criticism of the present study, it is important to note that such "uncontrolled" variables are simply part of comparative research (i.e., Bitterman, 1960). Although it is important to make testing conditions as equivalent as possible across species, it is never possible to know whether conditions were equivalent in the absence of an independent metric by which "correct" values for the relevant variables might be assigned.

Although the present results may be due to uncontrolled variables, they are also consistent with multiple origin hypothesis (Dougan et al., 1985, 1986; Hearst \& Gormley, 1976); that is, behavioral contrast may actually represent two (or more) distinct phenomena. Although contrast is operationally defined as a deviation from baseline responding, the observation of contrast in two situations does not necessarily mean that contrast is the same phenomenon in those two situations. Instead, contrast in the two situations might be different phenomena, which change as a function of different variables. For example, Dougan et al. (1986) showed that contrast may result from both matching (Herrnstein, 1970; Williams \& Wixted, 1986) and behavioral competition (Ettinger \& Staddon, 1982; Hinson \& Staddon, 1978; Staddon, 1982). Applied to the present results, the multiple origin hypothesis suggests that contrast in pigeons might represent a phenomenon that is fundamentally different from contrast in rats. If contrast in the two species were, in fact, two different phenomena, different functions relating deviations from baseline responding to baseline reinforcement rate might be expected. The different relationships observed between contrast and discrimination across species might also support a multiple origin hypothesis.

It is probably impossible to determine whether the uncontrolled variables explanation or the multiple origin explanation is correct. In fact, the two explanations may be logically identical, because the uncontrolled variables may actually be the sources of the multiple origins. Regardless of whether the present results are due to uncontrolled 
variables or whether contrast is a different phenomenon across species, they cause severe problems for all current theories of behavioral contrast. If the multiple origin hypothesis is true, current theories cannot explain the results because they each treat contrast as a single general process. If the uncontrolled variable explanation is correct, the theories cannot explain the present results because they do not predict the form of the functions relating contrast to baseline reinforcement rate.

According to matching theory (Equation 1), the magnitude of contrast should be a monotonically increasing function of the baseline reinforcement rate. Neither rats nor pigeons displayed such a function. The only way that Equation 1 could predict the form of the functions in Figure 1 is to assume that either the $m$ or $r_{0}$ parameters took on different values at the different scheduled rates of reinforcement, and did so differently across species. Although studies suggest that these parameters are not constant across schedule manipulations (Dougan \& McSweeney, 1985; McDowell \& Wood, 1985), the way in which they might change have not been specified. Thus, changes in the $m$ and $r_{0}$ parameters cannot explain the present results.

Competition theory (Equations 2 and 3) predicts a bitonic function relating the magnitude of contrast to the baseline rate of reinforcement. The function should be monotonically increasing when the rate of scheduled reinforcement is less than the rate of reinforcement for an alternative response (Equation 3), and monotonically decreasing when the rate of scheduled reinforcement is greater than the rate of reinforcement for an alternative response (Equation 2). Pigeons, in fact, showed a bitonic function quite similar to the functions predicted by competition theory (see Staddon, 1982, Figure 11-2, for comparison). Rats, on the other hand, did not show functions consistent with Equations 2 and 3.

According to the strong version of additivity theory, contrast should occur when pigeons peck keys but not when rats press bars. The present data support this prediction to the extent that contrast in pigeons was found more often than contrast in rats. The finding of reliable contrast in rats at high reinforcement rates, however, is problematic for additivity theory. Additivity theory still might be supported if it were assumed that barpressing in rats is sensitive to Pavlovian contingencies, but less so than keypecking in pigeons. If this were true, Pavlovian contingencies might affect barpressing only when the discrminative stimuli signaled large differences in reinforcement rate. Two factors argue against this conclusion. First, if barpressing is sensitive to the Pavlovian contingencies only when the difference between reinforcement rates are very large, then they should also show better discrimination on those schedules because Pavlovian responding should occur during $S+$ but not during $S-$. However, discrimination was poor at high rates of reinforcement in rats. Second, if Pavlovian responding does increase as a function of increasing differences between the reinforcement rates provided by multiple schedule components, then it should also do so in pigeons. However, pigeons showed reduced contrast at high rates of reinforcement.

The failure of contrast theories to explain the present results may be as much a failure of the theory-driven approach to contrast as it is a failure of the specific theories themselves. In recent years, the contrast literature has become overly burdened by theoretical models. Each of these models attempts to place contrast within a narrow theoretical framework. Such narrow definition seemingly contradicts the empirical data: Contrast is clearly a complex phenomenon. Contrast changes as a function of the baseline reinforcement rate (Dougan et al., 1985, 1986; McSweeney et al., 1986; Reynolds, 1963; Spealman \& Gollub, 1974), the availability of an alternative response and deprivation for the reinforcer produced by that alternative response (Dougan et al., 1986; Hinson \& Staddon, 1978), the relation between the discriminative stimulus and the reinforcer (Hearst \& Gormley, 1976; Keller, 1974; Schwartz, 1978), the form of the operant response (McSweeney, 1978, 1983), the relationship between multiple schedule components (Williams, 1979, 1980), and the duration of the multiple schedule components (Ettinger \& Staddon, 1982; Hinson, Malone, McNally, \& Rowe, 1978; McSweeney, 1982; McSweeney et al., 1986; Schwartz, 1978; Shimp \& Wheatly, 1971; Spealman, 1976; Todorov, 1972; Williams, 1979, 1980). These variables may also interact in unpredictable ways (e.g., Dougan et al., 1986). Finally, the present results suggest that contrast may represent different phenomena in different species. To date, no theoretical system has been able to capture the level of complexity suggested by the contrast literature.

The failure of the theory-driven approach suggests that a more basic, more inductive approach could be profitable. The contrast literature needs more parametric studies and fewer global theories. Only when we have a better grasp of the dimensions of the contrast phenomenon will global theories become a possibility.

\section{REFERENCES}

Allison, J. (1976). Contrast, inducton, facilitation, suppression, and conservation. Journal of the Experimental Analysis of Behavior, 25, 185-198.

Baum, W. M. (1974). On two types of deviation from the matching law: Bias and undermatching. Journal of the Experimental Analysis of Behavior, 22, 231-242.

BENINGER, R. J., \& KENDALL, S. B. (1975). Behavioral contrast in rats with different reinforcers and different response topographies. Journal of the Experimental Analysis of Behavior, 24, 267-280.

BitTerman, M. E. (1960). Toward a comparative psychology of learning. American Psychologist, 15, 704-712.

Bitterman, M. E. (1965). Phyletic differences in learning. American Psychologist, 20, 396-410.

Bitterman, M. E. (1975). The comparative analysis of learning. Science, 188, 699-709.

Blough, P. M. (1980). Behavioral and dimensional contrast in rats. Journal of the Experimental Analysis of Behavior, 33, 345-357. 
BoAKes, R. A. (1977). Performance on learning to associate a stimulus with positive reinforcement. In $\mathrm{H}$. Davis \& H. M. B. Hurwitz (Eds.), Operant-Pavlovian interactions (pp. 67-97). Hillsdale, NJ: Erlbaum.

Bradshaw, C. M., Szabadi, E., \& Bevan, P. (1978). Behavior of rats in multiple schedules of response-contingent and responseindependent food presentation. Quarterly Jourmal of Experimental Psychology, 30, 133-139.

Brown, P. L., JENkins, H. M. (1968). Auto-shaping of the pigeon's key-peck. Journal of the Experimental Analysis of Behavior, 8, 1-8.

CATANiA, A. C., \& Reynolds, G. S. (1968). A quantitative analysis of the responding maintained by interval schedules of reinforcement. Journal of the Experimental Analysis of Behavior, 11, 327-383.

Dougan, J. D., \& McSweEneY, F. K. (1985). Variation in Herrnstein's $r_{0}$ as a function of alternative reinforcement rate. Journal of the Experimental Analysis of Behavior, 43, 215-223.

Dougan, J. D., McSweeney, F. K., \& Farmer, V. A. (1985). Some parameters of behavioral contrast and allocation of interim behavior in rats. Journal of the Experimental Analysis of Behavior, 44, 325-335.

Dougan, J. D., McSweeney, F. K., \& Farmer, V. A. (1986). Behavioral contrast in competitive and non-competitive environments. Journal of the Experimental Analysis of Behavior, 46, 185-197.

Ettinger, R. H., \& STaddon, J. E. R. (1982). Behavioral competition, component duration and multiple-schedule contrast. Behaviour Analysis Letters, 2, 31-38.

GAMZU, E., \& SCHWARTZ, B. (1973). The maintenance of key pecking by stimulus-contingent and response-independent food presentation. Journal of the Experimental Analysis of Behavior, 19, 65-72.

Gurman, A. (1977). Positive contrast, negative induction, and inhibitory stimulus control in the rat. Journal of the Experimental Analysis of Behavior, 27, 219-233.

Gutman, A., Sutterer, J. R., \& Brush, F. R. (1975). Positive and negative behavioral contrast in the rat. Joumal of the Experimental Analysis of Behavior, 23, 377-383.

Hearsr, E. (1987). Extinction reveals differential responding on a feature-negative discrimination task. Journal of Experimental Psychology: Animal Behavior Processes, 13, 52-64.

HeARST, E., \& GormLey, D. (1976). Some tests of the additivity (autoshaping) theory of behavioral contrast. Animal Learning \& Behavior, 4, 145-150.

HeARST, E., \& JENkins, H. M. (1974). Sign tracking: The stimulusreinforcer relation and directed action. Austin, TX: Psychonomic Society.

HENKE, P. G. (1972). Amygdalectomy and mixed reinforcement schedule contrast effects. Psychonomic Science, 28, 301-302.

Herrnstein, R. J. (1970). On the law of effect. Journal of the Experimental Analysis of Behavior, 13, 243-266.

Hinson, J. M., Malone, J. C., McNally, K. A., \& Rowe, D. W (1978). Effects of component length and of the transitions among components in multiple schedules. Journal of the Experimental Analysis of Behavior, 29, 3-16.

Hinson, J. M., \& STADDON, J. E. R. (1978). Behavioral competition: A mechanism for schedule interaction. Science, 202, 432-434.

KELLER, K. (1974). The role of elicited responding in behavioral contrast. Journal of the Experimental Analysis of Behavior, 21, 249-257.

MCDOWELL, J. J., \& WOOD, H. M. (1985). Confirmation of linear system theory prediction: Rate of change of Herrnstein's $k$ as a function of response force requirement. Journal of the Experimental Analysis of Behavior, 43, 61-73.

MCSWEENEY, F. K. (1978). Negative behavioral contrast on multiple treadle-press schedules. Journal of the Experimental Analysis of Behavior, 29, 463-473.

MCSWEeney, F. K. (1982). Prediction of concurrent treadle-pressing from simple schedule performance. Behaviour Analysis Letters, 2 , 11-20.

MCSWeeney, F. K. (1983). Positive behavioral contrast when pigeons press treadles during multiple schedules. Journal of the Experimental Analysis of Behavior, 39, 149-156.

MCSweeney, F. K., Dougan, J. D., Higa, J., \& Farmer, V. A (1986). Behavioral contrast as a function of component duration and baseline rate of reinforcement. Animal Learning \& Behavior, 14, 173-183.

MCSWEeney, F. K., EtTINGer, R. H., \& Norman, W. D. (1981). Three versions of the additive theories of behavioral contrast. Journal of the Experimental Analysis of Behavior, 36, 285-297.

McSweEney, F. K., \& Norman, W. D. (1979). Defining behavioral contrast for multiple schedules. Journal of the Experimental Analysis of Behavior, 32, 457-461.

NAlLaN, G. B., \& McCoy, D. F. (1979). Positive contrast in the rat; A test of the additivity theory. American Joumal of Psychology, 92, 449-461.

Pear, J. J., \& WILKIE, D. M. (1970). Behavioral contrast in mixed schedules of reinforcement. Psychonomic Science, 20, 167-167.

PerT, A., \& Gonzalez, R. C. (1974). Behavior of the turtle (Chrysemys picta picta) in simultaneous, successive, and behavioral contrast situations. Journal of Comparative \& Physiological Psychology, 87, 526-538.

Rachlin, H. (1973). Contrast and matching. Psychological Review, 80, 217-234.

REYNOLDS, G. S. (1961). Behavioral contrast. Joumal of the Experimental Analysis of Behavior, 4, 57-71.

Reynolds, G. S. (1963). Some limitations on behavioral contrast and induction during successive discrimination. Journal of the Experimental Analysis of Behavior, 6, 131-139.

SCHWARTZ, B. (1978). Stimulus-reinforcer contingencies and local behavioral contrast. Journal of the Experimental Analysis of Behavior, 29, 297-308.

Schwartz, B., \&amzu, E. (1977). Pavlovian control of operant behavior. In W. K. Honig \& J. E. R. Staddon (Eds.), Handbook of operant behavior (pp. 53-97). Englewood Cliffs, NJ: Prentice-Hall.

Shimp, C. P., \& Wheatly, K. L. (1971). Matching to relative reinforcement frequency in multiple schedules with short component duration. Joumal of the Experimental Analysis of Behavior, 15, 205-210.

Spealman, R. D. (1976). Interactions in multiple schedules: The role of the stimulus-reinforcer contingency. Journal of the Experimental Analysis of Behavior, 26, 79-93.

Spealman, R. D., \& Gollub, L. R. (1974). Behavioral interactions in multiple variable-interval schedules. Journal of the Experimental Analysis of Behavior, 22, 471-481.

STADDON, J. E. R. (1982). Behavioral competition, contrast and matching. In M. L. Commons, R. J. Herrnstein, \& H. Rachlin (Eds.), Quantitative analyses of behavior: Vol. 2. Matching and maximizing accounts (pp. 549-568). Cambridge, MA: Ballinger.

Terrace, H. S. (1968). Discrimination learning, the peak shift, and behavioral contrast. Journal of the Experimental Analysis of Behavior, 11, 727-741.

ToDorov, J. C. (1972). Component duration and relative response rates in multiple schedules. Journal of the Experimental Analysis of Behavior, 17, 45-49.

UhL, C. N., Homer, A. L. (1974). Omission training compared with yoked controls and extinction in multiple-schedule discrimination learning. Animal Learning \& Behavior, 2, 317-324.

WILKIE, D. M. (1972). Variable-time reinforcement in multiple and concurrent schedules. Journal of the Experimental Analysis of Behavior, $17,59-66$.

Williams, B. A. (1979). Contrast, component duration, and the following schedule of reinforcement. Journal of Experimental Psychology: Animal Behavior Processes, 5, 379-396.

Williams, B. A. (1980). Contrast, signaled reinforcement, and the relative law of effect. American Journal of Psychology, 93, 617-629.

Williams, B. A. (1983). Another look at contrast in multiple schedules. Journal of the Experimental Analysis of Behavior, 39, 345-384.

Williams, B. A., \& WIXTED, J. T. (1986). An equation for behavioral contrast. Journal of the Experimental Analysis of Behavior, 45, 47-62.

\section{NOTE}

1. Depending on the definition used, the finding of contrast-like effects in the absence of discrimination may or may not be considered a true instance of behavioral contrast. According to Reynolds's (1961) 
original definition of contrast, such a result would constitute positive induction as opposed to contrast. This is because Reynolds defined contrast as the relationship between two dependent variables (the response rates in the two components). More recent definitions (McSweeney \& Norman, 1979; Williams, 1983) describe contrast as a relationship be- tween an independent variable (reinforcement rate in the changed component) and a dependent variable (response rate in the constant component). The present paper uses this more recent definition, so the finding of contrast-like effects in the absence of discrimination is considered a true instance of behavioral contrast.

(Manuscript received March 11, 1988,

revision accepted for publication August 29, 1988.) 